\title{
La revolución universitaria de Julio V. González
}

The university revolution of Julio V. González

\begin{abstract}
ALEX E. RATTO
Profesor de Historia, graduado de la Facultad Humanidad y Artes (UNR). Becario CONICET desarrollando actividades en ISHIR (Investigaciones Socio-históricas Regionales). Docente terciario y universitario. Correo electrónico: rattoalex@hotmail.com
\end{abstract}

\section{Resumen}

Este trabajo intenta explorar la construcción de una de las imágenes que se tiene sobre la Reforma Universitaria a poco tiempo de sus acontecimientos, una imagen que intenta potenciar el carácter revolucionario de los sucesos de Córdoba de 1918. Para ello, concentraremos nuestra atención en la producción de Julio V. González, unos de los protagonistas que postularon la necesidad de expandir el desconecto de una nueva generación de universitarios fuera del marco de la Universidad.

Hijo de Joaquín V. González, unos de los líderes modernista de la generación del 80, Julio V. González participó desde el inicio en la Reforma Universitaria. En 1919 se convirtió en el presidente más joven de la FUA. Y más tarde escribió trilogía donde teorizo sobre la reforma. Iniciada con La revolución universitaria de 1922, a la cual le siguieron La reforma universitaria de 1927) y La emancipación universitaria de 1929.

\section{Abstract}

This work tries to explore the construction of one of the images that one has about the University Reform shortly after its events, an image that tries to enhance the revolutionary character of the events of Córdoba in 1918. For this, we will concentrate our attention on the production by Julio V. González, one of the protagonists who postulated the need to expand the disconnection of a new generation of university students outside the framework of the University. Son of Joaquín V. González, one of the modernist leaders of the generation of 80 , Julio V. González participated from the beginning in the University Reform. In 1919 he became the youngest president of the FUA. And later he wrote a trilogy where I theorize about the reform. Initiated with the university revolution of 1922, which was followed by the university reform of 1927) and the university emancipation of 1929 .

The objective of this work is to 
El objetivo de este trabajo es analizar la narración de Julio $\mathrm{V}$. González de los hechos y principios de las Reforma del 18, en busca de encontrar sus particularidades. De esta forma, focalizaremos nuestro estudio en la interpretación de los antecedentes históricos de la Reforma señalados establecidos por él (advenimiento del radicalismo, I Guerra Mundial y la revolución rusa), como así también, de la valoración del uso de la violencia en su primer obra, La revolución universitaria de 1922.

Palabras clave

Reforma universitaria - Revolución Universitaria - movimiento estudiantil - Julio V. González Violencia analyze the narration of Julio $\mathrm{V}$. González of the facts and principles of the Reformation of 18, in search of finding its particularities. In this way, we will focus our study on the interpretation of the historical background of the Reformation established by him (advent of radicalism, World War I and the Russian Revolution), as well as the evaluation of the use of violence in his first work, The university revolution of 1922 .

\section{Keywords}

University reform - University Revolution - student movement Julio V. González - Violence

\section{Introducción}

El presente artículo intenta en profundizar el estudio de acerca el fenómeno de la reforma universitaria junto con su movimiento estudiantil. Mucho, en el sentido que nos encontramos con una gran cantidad de material producido por sus protagonistas. Pero en cuando nos vamos acercando a nuestros días son pocos los artículos y libros que se realizaron sobre el mismo, en tanto hacemos una comparación con los primeros. Y que salvando excepciones, pocas son las innovaciones al respecto. El objetivo de este trabajo es, en primer lugar recordar los hechos y principios de las reformas, haciendo hincapié en la narrativa de Julio V. González. Para finalizar con un análisis interpretativo de los antecedentes históricos de la Reforma señalados por él (advenimiento del radicalismo, I Guerra Mundial y la revolución rusa), como así también, de la valoración del uso de la violencia en su primer obra, La revolución universitaria de 1922.

\section{El grito de Córdoba}

La Universidad de Córdoba, es la institución educativa más antigua del país. Fundada en 1613 gracias a un acuerdo del Papado y el Imperio español, tuvo desde sus orígenes una orientación eminentemente teológica. Solo a fines del siglo XVIII se crearon cátedras de derecho civil que permitieron otorgar títulos de grado en Derecho. Pese a su antigüedad, la universidad de Córdoba solo contaba con el ocho por ciento de los seis mil alumnos matriculados en las universidades argentinas hacia 1910. Era en sus aulas, donde se protegía el favor religiosos de 
antaño y el mantenimiento del orden conservador. Las clases dominantes desconfiaban de la creciente irrupción en los claustros de los sectores sociales en ascenso, lo cual podía conducir a una pérdida del control exclusivo que históricamente habían ejercido sobre la institución.

Esta desconfianza no se basa en temores sin fundamentos. En poco tiempo comenzaron a solidificarse el reclamo de cambio dentro de la universidad. Así, los principios estudiantiles de la reforma universitaria de 1918 fueron la autonomía y gobierno de la universidad. Con lo cual se buscaba deja de ser simples y pasivos receptores de las lecciones repetidas. Para ello reclamaban la libertad de cátedra, asistencia libre, docencia libre, periodicidad de los actos universitario, el carácter público y gratuito de la enseñanza y, seminarios y demás formas de una intervención activa del estudiante en todos los espacios académicos.

Al reclamar la participación estudiantil en el gobierno universitario, el movimiento reformista quiso hacer del estudiante el centro del acto educativo e integrarlo en el funcionamiento. Que un estudiante participara en un co-gobierno de igual a igual con los docentes tradicionales, no tenía antecedentes en el mundo contemporáneo.

La Reforma sería la bandera de varias generaciones de jóvenes latinoamericanos que lucharían por conquistar sus demandas de libertad de cátedra, libre elección de autoridades, co-gobierno democrático, reforma de los sistemas de enseñanza, apertura ideológica, autonomía. Esta lucha abarcaría prácticamente a todo el continente y luego de la segunda guerra llegaría a Europa, no así a los EE.UU., que perdurarían en sus universidades más cerradas.

Debemos destacar que a diferencia del mayo francés, donde el pleito con las autoridades había comenzado con un problema de alcoba. El estallido del movimiento estudiantil en el 18 tuvo que tuvo motivo la lucha política por una universidad más democrática en el marco por la elección de nuevas autoridades.

De esta forma sus protagonistas impugnaban el espíritu conservador de la Universidad de Córdoba:

"La juventud universitaria de Córdoba afirma que jamás hizo cuestión de nombres ni de empleos. Se levantó contra un régimen administrativo, contra un método docente, contra un concepto de autoridad. Las funciones públicas se ejercitaban en beneficio de determinadas camarillas. No se reformaban ni planes ni reglamentos por temor de que alguien en los cambios pudiera perder su empleo. La consigna de «hoy para ti, mañana para mí», corría de boca en boca y asumía la preeminencia de estatuto universitario. Los métodos docentes estaban viciados de un estrecho dogmatismo, contribuyendo a mantener a la universidad apartada de la ciencia y de las disciplinas modernas. Las elecciones, encerradas en la repetición interminable de viejos textos, amparaban el espíritu de rutina y de sumisión. Los cuerpos universitarios, celosos guardianes de los dogmas, trataban de mantener en clausura a la juventud, creyendo que la conspiración del silencio puede ser ejercitada en contra de la ciencia. Fue entonces cuando la oscura universidad mediterránea cerró sus puertas a Ferri, a Ferrero, a Palacios y a otros, ante el temor de que fuera perturbada su plácida 
ignorancia. Hicimos entonces una santa revolución y el régimen cayó a nuestros golpes." (Roca, 2006: 54-55)

El inicio de lo que luego fue la Reforma del 18, se produjo un años antes cuando los estudiantes cuestionaron la legitimidad del rector y de los decanos, denunciando el arcaísmo de los reglamentos y reclamando modificaciones a los planes de estudios. Las presentaciones estudiantiles fueron rechazadas una y otra vez. Y para fines de 1917, los centros de estudiantes de Ingeniería y medicina protestaron por la modificación del régimen de asistencia a clase y la supresión del internado del Hospital de Clínicas. Al no dar respuestas las autoridades a estos reclamos de constituyo el Comité Pro Reforma a inicios de 1918, que proclamó la huelga general el 31 de marzo. El 2 de abril, Consejo Superior decidió clausurar la Universidad y dos días después el Comité Pro Reforma pidió la intervención del gobierno nacional, la cual se efectivizó una semana después cuando el presidente Yrigoyen nombró interventor al entones procurador general de la Nación, José Nicolás Matienzo. Mas tardé, el Comité Pro Reforma se disuelve para dar nacimiento a la Federación Universitaria Argentina (FUA).

En la brevedad Matienzo hizo aprobar el estatuto que reemplazaría al de 1893 al que calificó de restrictivo por cuanto excluía a los profesores dejando el gobierno en manos de cuerpos vitalicios. Con la cual, propuso la renovación de las autoridades en una asamblea con la totalidad de los profesores, pero sin el voto estudiantil.

En la Asamblea Universitaria del 15 de junio donde se elegía nuevo rector se presentaron tres candidatos: Enrique Paz Martínez como representante del movimiento estudiantil, Antonio Nores por la Corda Frates ${ }^{1}$; y Alejandro Centeno, candidato inerte medio. Lo cierto que aunque los candidatos reformistas tenían un peso muy importante en la confracción de la Asamblea, ninguno de los postulantes pudo obtener en las dos primeras votaciones la necesaria mayoría. Se desarrolló entonces una tercera, esta vez entre los dos postulados candidatos más votados (Nores y Martinez Paz), y los simpatizantes de Centeno dieron sus votos al primero. Sin embargo, aquél no alcanzo a ser proclamado rector por la irrupción violenta de los estudiantes dispuestos a no permitir que se burlara la voluntad general. Sin duda, este hecho marco una desilusión de la esperanza depositada en los docentes como agentes de cambio. A partir de allí, un grupo de estudiantes vera necesario la intervención directa dentro del gobierno universitario.

De esta forma, el conflicto se extendió, y la efervescencia estudiantil llevó al desarrollo de marchas que recorrieron la ciudad y a distintas concentraciones que contaron con un amplio apoyo de la comunidad. Sin embargo, la anunciada intervención nacional no llegaba. Entonces, un grupo de ochenta estudiantes tomaron por asalto la universidad y eligieron nuevas autoridades, el 9 de septiembre de ese año.

\footnotetext{
${ }^{1}$ Congregación secreta constituida por muchos notables de la ciudad y destinadas a mantener sus privilegios y apoyar a sus miembros.
} 
La ocupación fue pacífica, y al momento de la intervención policial los ocupantes no ofrecieron la resistencia alguna. El disgustos de la autoridades provinciales, se materializo en un inicio de proceso a los participantes de la toma, y muchos de sus líderes fueron encarcelados. Pero la acción de los estudiantes tuvo el efecto buscado de llamar la atención de las autoridades nacionales. De esta forma, se logra una segunda intervención nacional en septiembre. Y en octubre del mismo año es electo Eliseo Soaje, representante que hacía eco de los reclamos reformadores del movimiento estudiantil. Lo que significó la primera victoria del movimiento, a pesar que solo fuera solo una batalla de una guerra más prolongada, ya que con el golpe del 30 , se esfuman los avances y victorias conseguidos hacía más de una década atrás. El nuevo gobierno declaró que unos de sus objetivos era acabar con la "anarquía universitaria”. Esto se llevó a cabo a través de la persecución de organizaciones estudiantiles y la restitución de las fuerzas antirreformistas dentro de los directivos universitarios.

\section{La revolución universitaria de Julio V. González}

Julio V. González nació en 1899, y fue unos de los protagonistas y defensores del movimiento estudiantil del 18, como así, también un autor prolifero sobre el tema. Era hijo del conocido intelectual y político reformista Joaquín V. González. Su padre fue el impulsador de la fallida Ley del Trabajo de 1904, que pretendía en forma cooptativa y no represiva solucionar la insipiente cuestión obrera del país. Además, en 1905 funda la Universidad de La Plata, de la que fue presidente y docente hasta 1918. En esas mismas aulas, Julio cursa sus estudios universitarios de Derecho.

Su temprana participación estudiantil lo hizo unos de los primeros protagonista de la Reforma universitaria de 1918. Un año antes había escrito una Relación sobre la huelga universitaria, donde mostraba su interés de representante estudiantil frente a los consejos académicos.

En julio de 1918 se encuentra en Córdoba acompañando el movimiento estudiantil como representante de la Federación Universitaria de La Plata, y secretario en el "Primer Congreso Nacional de Estudiantes Universitario". Luego, en el 1919 es consagrado como el presidente más joven de la Federación Universitaria Argentina (FUA). En el períodos 1923-25 y 1929-30 es consejero en la Facultad de Derecho de Buenos Aires. El 14 de diciembre de 1929, acepta el decanato interino a solicitud de los estudiantes que habían tomado esa facultad. Mientras que en 1925 fue propuesto como candidato para la presidencia de la Universidad de La Plata.

Su definición como antiimperialista lo llevo a la participación, en 1925, como fundador y miembro titular de la Unión Latinoamérica, junto a José Ingeniero, Aníbal Ponce, Alfredo Palacios.

Su pensamiento político liberal, socialista y antiimperialista lo llevaron a las filas del Partido Socialista (PS). Sin embargo en 1922, tiene una breve afiliación al Partido Democrático Progresista (PDP). Influenciado por el primer auge del APRA peruano, cinco años más tarde, intenta la constitución del Partido Nacional Reformista. Entre las causas del fracaso de la constitución del partido 
se hallan las desconfianzas juvenil hacia la política "grande", la posición excesivamente paternalista del universitario de la época frente al resto de la sociedad; y además porque ya esa altura comenzaba a evidenciarse la crisis de los partidos políticos y los vientos del autoritarismo.

Será 1930 un año decisivo en su vida política. Tras el golpe de Uriburu es vapulado como "agitador universitario", tituló que llevó orgulloso, pero que también le reportó cárcel y persecución, situación que se repetiría nuevamente en 1943. En esos años se produce su acercamiento definitivo al PS, siendo electo en 1940 diputado como representante de esta fuerza. Como legislador, ante de su destitución en 1943, defendió los principios reformista en un proyecto parlamentario sobre la universidad y la nacionalización del petróleo.

Con el peronismo al poder, su propio partido silencia y destierra su figura dentro del mismo. El motivo fue su reclamo por un nuevo programa radical que abandonara la estrategia del programa minino, capaz de devolverle el papel de partido de clase y anticapitalista al PS. Para Julio V. González, el partido se hallaba en un punto muerto debido a la mutación del socialismo en un representante liberal de izquierda del ala antiperonista. Su propuesta se basa en el reconocimiento de las mejoras de la condición obrera dentro del capitalismo que había hecho el socialismo, pero que en el reconocimiento de las mejoras efectivas del peronismo sobre los trabajadores poco quedaría por realizar en esta materia. Por ello, según él, el PS debía adoptar el programa máximo del socialismo.

Ocurrida la Revolución Libertadora, y de regreso de un viaje por Europa, intentaría reanudar sus tareas docentes cuando la muerto lo sorprende a fines de 1955.

Entre sus escritos sobre la materia, encontramos la ya cita Revolución universitaria, La significación social de la reforma Universitaria de 1924, La reforma universitaria de 1927 en dos tomos y La emancipación universitaria de 1929.

En sus aportes a la interpretación y caracterización de la Reforma Universitaria Julio V. González, encontramos el discurso de quien desarrolla, junto a Deodoro Roca, una postura de izquierda dentro del proceso de reformista del 18. La cual, puede ser entendida como la visión de quienes participaron dentro de los sucesos y buscaron, o encontraron en su mismo devenir, una transformación más amplia que la renovación interna de la universidad. Ellos se piensan parte de un proceso, o progreso, de la sociedad que tiene como fin liberar al hombre de las divisiones de clases, y establecer relaciones más justa e igualitarias. Para ellos, el rasgo que le otorgaba significado social y trascendencia histórica al movimiento era el acercamiento que había posibilitado entre "masas estudiantil y masa proletaria. Las dos luchaban por los mismos ideales y eran víctima de la represión de los mismos grupos dominantes.

Julio V. González, contribuye a la construcción de un mito romántico colocando al proceso dentro de una genealogía de la historia universal. De esta forma, concibe a la reforma universitaria como causa y efectos del advenimiento radical en 1916, la I Guerra Mundial y la revolución Rusa. Es decir, tres antecedentes que explican su aparición como producto de su tiempo. 
Con la I Guerra Mundial marcaba el fin de la belle époque, demostrando la crisis del nacionalismo exacerbado y de la iluminación de progreso gradual e indefinido. Por su parte el advenimiento del radicalismo, para él, pone fin a un período de la sociedad argentina donde las generaciones pasadas eran incapaces de afrontar la solución de los problemas planteados por la colectividad. No obstante a la pregunta ¿Qué traía esto? Él contesta:

"Concretamente, nada. Llegaba a destruir (...). Pero, no obstante ello, no era una tendencia anárquica y disolvente: era una fuerza en cierto modo demagógica, es decir, esencialmente creadora y fecunda. Arrasaba, pero dejando el limo fértil de la sensibilidad netamente popular llegada a las esferas del gobierno". (González, 1984: 11).

Pero frente a esta incertidumbre y vacío, será la revolución rusa la que encaminara moral e ideológicamente los nuevos tiempos:

"En medio, de la desorientación, de la incertidumbre y del escepticismo que domina a los espíritus, aparece en el escenario la Revolución Rusa trayendo luz nueva, ofreciendo ideales de humana redención, levantando una voz acusadora y profética al mismo tiempo" (González, 1984: 11).

Es así como él observa el cuadro de la historia en donde se enmarca la Reforma Universitaria. Ante la incertidumbre de la guerra, el advenimiento radical que sirvió para poner fin a un período y allanar en el suelo para el gobierno de la colectividad, y la guía moral e ideológica de la Revolución Rusa. Aparece la Reforma Universitaria como la abandera del progreso modernizador en el país y en América Latina. Pero sin embargo, tal cambio profundo nunca se produjo.

Para poder entender esto es necesario poner en discusión la determinación de estos de los antecedentes. Si la Gran Guerra era sin duda la manifestación de que los bellos tiempos se había terminado, el fruto de la incertidumbre hay que buscarlos en otro proceso mucho mayor. Este era el avance del capitalismo como medio de producción hegemónico y la vorágine social que género la modernidad, productor y fruto del mismo. El otro aspecto, más que vacío y terreno fértil con el advenimiento del radicalismo, encontramos la limitación de la destrucción del viejo orden por el mismo, la continuidad e intensificación de la lucha de clases, junto con la semilla del fortalecimiento de las corporaciones. Las misma que van a cuestionar régimen democrático de masas, que culminara con el golpe del 30 . Y si la Revolución Rusa significo una primera luz para las jóvenes generación, esta se fue apagando con el paso del tiempo.

Por último queremos resaltar la interpretación de los usos la violencia en la accionar de un movimiento como el de la Reforma del 18. Para Julio V. González:

"Si la situación insostenible de la universidad de Córdoba con sus malos profesores y su anticuado régimen de gobierno, impuso como único medió de resolver el problema, el desacato y la violencia revolucionaría, así lo hizo el estudiante cordobés, apoyando unánimemente por los de toda república. 
Pero también cuando fue menester elevarse a un plano superior, para engolfar se en el estudio meditado y sereno de las leyes, estatutos u ordenanzas que obraban como causas de los vicios inveterados y profundos del régimen educacional universitaria, supo desempeñarse en estas funciones con la misma eficacia con que lo hicieron en la primera.” (González, 2008: 78-79).

Así observamos que el uso de la violencia en caso último, tras haber agotado otras instancias y ante la inamovilidad de sus interlocutores, es legitimado por él. Pero en relación con él estudio meditado y sereno, esta se halla un escalón más debajo de él. Sin embargo, en esta jerarquización no hay condena, sino todo lo contrario. Existe en Julio V. González una reivindicación del uso de la violencia revolucionaria en todo lugar $y$ en todo momento en que las circunstancias lo ameriten. En ella se expresa el ideal de cambio y de futuro.

Terminamos este breve ensayo con el siguiente recuerdo:

“El derribamiento de una estatua, erguida frente a la Compañía de Jesús y la universidad, simbolizaba el espíritu reaccionario amenazando perpetuarse fundido en bronce, a despecho de todos los esfuerzos y de todos los sacrificios, es un vandalismo sencillamente hermoso." (González, 2008: 18).

Recibido: $31 / 10 / 2017$

Aceptado: $27 / 11 / 2017$

\section{Bibliografía}

ALTAMIRANO, C. (2002). Ideologías políticas y debates cívicos. En TORRES, JUAN RICARDO (dir.), Los años peronistas (1943 - 1955), Nueva Historia Argentina, Tomo VI, Buenos Aires: Ed. Sudamericana.

BUCHBINDER, P. (2008). ¿Revolución en los claustro? La reforma Universitaria de 1918, Buenos Aires: Ed. Sudamericana.

CIRIA, A. y SANGUINETTI, H. (2006) La reforma universitaria (1918 - 2006). Santa Fe: Editorial Universidad Nacional del Litoral.

CHIROLEU, A. (2002). La reforma universitaria. En FALCON, R. (dir.), Democracia, conflicto social y renovación de ideas (1916 - 1930), Nueva Historia Argentina, Tomo VI, Buenos Aires: Ed. Sudamericana.

GONZALE, J. V. (2008). La revolución Universitaria. Santa Fe: Cámara de diputados de la provincia de Santa Fe-

GONZALE, J. V. (1984), Significación social de la reforma universitaria. Buenos Aires Offset Tabare S.R.L.

ROCA, D. (2006). Manifiesto Liminar. En CIRIA, A. y SANGUINETTI, H. (2006) La reforma universitaria (1918 - 2006). Santa Fe: Editorial Universidad Nacional del Litoral. 